\title{
Assessing potential seismic activity in Vrancea, Romania, using a stress-release model
}

\author{
Masajiro Imoto ${ }^{1}$ and Nobuo Hurukawa $a^{2,3}$ \\ ${ }^{1}$ National Research Institute for Earth Science and Disaster Prevention, 3-1 Tennodai, Tsukuba-shi, Ibaraki-ken 305-0006, Japan \\ ${ }^{2}$ National Center for Seismic Risk Reduction, Ministry of Transport, Construction and Tourism, Bucharest, Romania \\ ${ }^{3}$ International Institute of Seismology and Earthquake Engineering Building Research Institute, \\ 1 Tachihara, Tsukuba-shi, Ibaraki-ken 305-0802, Japan
}

(Received July 29, 2005; Revised July 20, 2006; Accepted July 24, 2006; Online published December 25, 2006)

\begin{abstract}
Over the last 500 years, an average of five intermediate-depth earthquakes of $M w=7$ and larger have occurred during each 100-year period in Vrancea, Central Romania. We have therefore attempted to assess the long-term seismic hazards in Vrancea using a stress-release (SR) model which models the elastic rebound theory in a stochastic process. The hypocenter catalog, ROMPLUS, provided by the National Institute for Earth Physics (NIEP), was adopted for the study. We only used data on earthquakes located in Vrancea and applied the SRmodel to data sets of earthquakes with a magnitude of 7.0 and larger for three different time periods. Renewal models, such as the Brownian and Weibull model, were also applied to the same data set, but these did not perform as well as the SR-model. The SR-model can assess future earthquake probability and has identified that the probability of an earthquake occurring in Vrancea in a 5-year period exceeds $40 \%$ by the end of this decade.
\end{abstract}

Key words: Long-term probability, hazard, stress release model, Vrancea, Romania.

\section{Introduction}

Large, intermediate-depth earthquakes occur frequently in Vrancea, Central Romania. Over the past 500 years, an average of five earthquakes of $M=7.0$ and greater have occurred each 100-year period. In 1977, an $M=7.4$ ( $M w=$ 7.5) earthquake caused severe damage in Bucharest, leaving many buildings vulnerable. The next large earthquake will probably cause severe damage there once again, so an assessment of the long-term potential for seismic activity in Vrancea is critical.

The seismic activity in Vrancea is characterized by location-specific features: (1) strong earthquakes occur at intermediate depths in a very small volume; (2) Vrancea is located at the SE corner of the Carpathian arc; (3) there is no evidence of an active subduction system. Most of the current seismotectonic models incorporate the possibility of the interaction of a paleo-subduction zone with recent subduction and include the concept of an old subducted slab sinking gravitationally (e.g. Fuchs et al., 1979; Wenzel et al., 1999; Sperner et al., 2004). These features imply that the Vrancea seismicity is not represented only by a simple subduction system between two plates.

Renewal-process models, such as the Brownian, lognormal, Weibull, and Gamma models, are normally used for assessing the long-term probability of characteristic earthquake sequences of quasi-periodic recurrence (Working Group on California Earthquake Probabilities, 1990, 1999; Shimazaki et al., 1999). These renewal models are

Copyright (c) The Society of Geomagnetism and Earth, Planetary and Space Sciences (SGEPSS); The Seismological Society of Japan; The Volcanological Society of Japan; The Geodetic Society of Japan; The Japanese Society for Planetary Sciences; TERRAPUB theoretically based on the relative movement between two plates. The seismicity in Vrancea demonstrates neither quasi-periodic recurrence nor simple relative movement between two plates. As such, the tectonic environment of the region remains uncertain, and the major stress regime of the region is not well defined. Therefore, renewal models are not the best approach for an assessment of the long-term seismic hazards in Vrancea.

We therefore have applied the stress-release model (SRmodel; see Zheng and Vere-Jones, 1991) to assess the seismic hazard in Vrancea. This model formulates the gradual build-up of stress by tectonic movements and release of that stress in the form of earthquakes. Zheng and VereJones (1994) applied the SR-model to the seismic activity in southwestern Japan, including both interplate and intraplate earthquakes. Imoto (2001) applied the SR-model to the Nankai earthquake sequence, also in southwestern Japan, comparing the model with renewal models and concluding that the SR-model was better than the renewal model in terms of information quantity. These investigations imply that the SR-model is applicable to both characteristic earthquake sequences and events governed by a simple stress regime.

In this study, we applied the SR-model to data under a few reasonable conditions and estimated the probability of future large earthquakes in Vrancea.

\section{Method}

Following the formulation of the SR-model by Zheng and Vere-Jones $(1991,1994)$, we express the hazard function, $\lambda(t)$, as

$$
\lambda(t)=\exp \left\{a_{1}+a_{2} t-a_{3} S(t)\right\}
$$



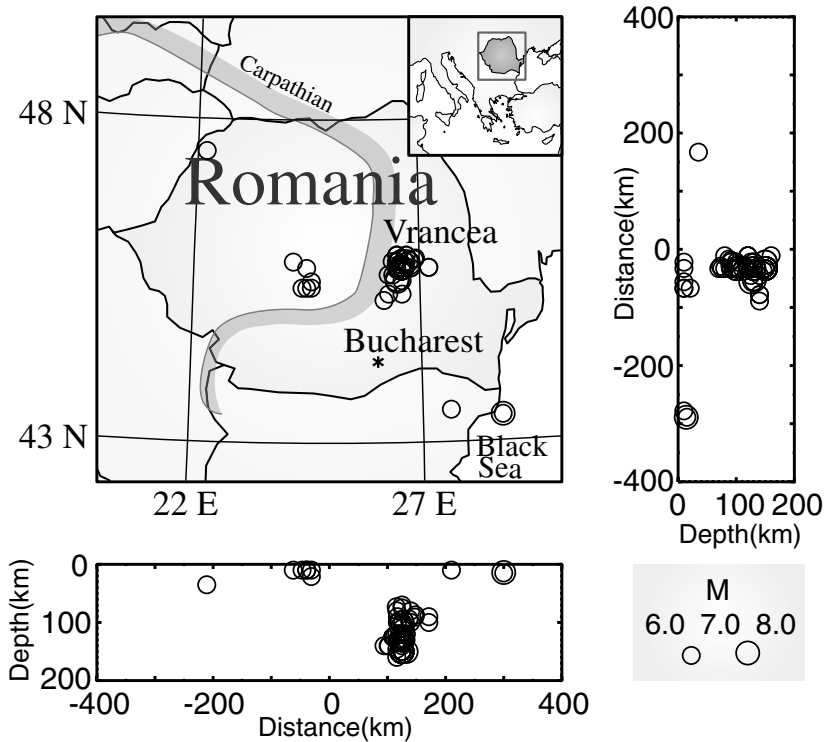

$\mathrm{M}$

6.07 .08 .0 00

Fig. 1. Hypocenter distribution of earthquakes in Romania which are registered in the ROMPLUS catalog. Earthquakes with magnitude of 6.0 or greater that occurred between 1500 and 2000 are illustrated. Epicentral distribution and two vertical cross sections along North-South and East-West are illustrated.

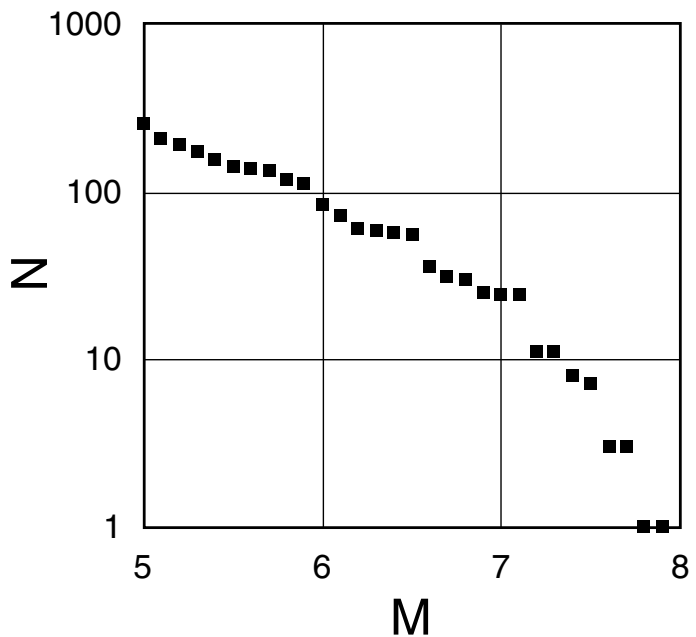

Fig. 2. Magnitude-frequency relation for earthquakes of magnitude 5.0 and greater. Only earthquakes for the period from 1500 to 2000 that occurred at depths from 60 to $180 \mathrm{~km}$ are considered.

where $S(t)$ represents stress released by events prior to the time of assessment as:

$$
S(t)=\sum_{i=1}^{k} S_{i} .
$$

The stress drop of the $i$ th event, $S_{i}$, is related to its magnitude $M_{i}$ by the formula

$$
S_{i}=10^{0.75 M_{i}}
$$

where only earthquakes larger than a certain threshold magnitude are taken into account for the stress release in Eq. (2). The value of 0.75 is derived by considering the relationship between stress and strain energy combined with the Gutenberg-Richter relation, $\log _{10} E=1.5 M+$

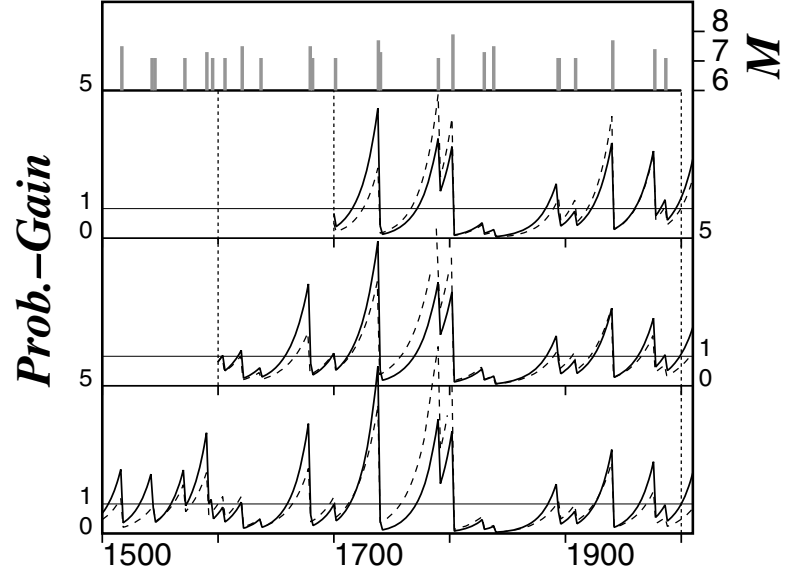

Fig. 3. Hazard functions of earthquakes $(M \geq 7.0)$ for three different periods: $1500-2000,1600-2000$, and 1700-2000. Hazard functions are plotted in units of the Poisson rate (18 events per 5000 years). The earthquake times and magnitudes are specified at the top of the figure. Hazard functions obtained by excluding five earthquakes (with asterisks in Table 1) are indicated by dashed lines.

CONSTANT (Zheng and Vere-Jones, 1994). The second term of the exponent in Eq. (1) relates to stress built up linearly with time. In our analysis, we do not consider the effects of distances between events, unlike the linked stress release model (Lu et al., 1999; Bebbington and Harte, 2001). With this hazard function, the likelihood function in the point process is given as

$$
L_{s}=\exp \left\{-\int_{0}^{t} \lambda(t) d t\right\} \cdot \prod_{i=1}^{k} \lambda\left(t_{i}\right) .
$$

To compare the SR-model with renewal models, we fit the Brownian, lognormal, Weibull, and Gamma models (with two adjusted parameters) to data obtained for the time intervals between successive events (Utsu, 1984; Nishenko and Buland, 1987). For this comparison, the Akaike information criterion (AIC; Akaike, 1977; Sakamoto et al., 1983) procedure was used. AIC is defined by

$$
A I C=-2 \cdot \ln L_{s}+2 m,
$$

where $m$ is the number of fitted parameters in the model. In our case, there were three free parameters. The difference in $A I C$ s between a given model and the stationary Poisson model (denoted as $\triangle A I C$ ) was adopted as our standard for model selection, defined by

$$
\triangle A I C=A I C o-A I C p
$$

where $o$ refers to the baseline model and $p$ refers to the proposed model. When the proposed model is better fitted to the data than the Poisson, $\triangle A I C$ takes a greater positive value.

\section{Data and Results}

We used a Romanian earthquake catalog, called ROMPLUS, which was prepared by Oncescu et al. (1999) and is maintained by the National Institute for Earth Physics (NIEP). Oncescu et al. (1999) converted different magnitude scales into moment magnitude, Mw, in order to homogenize and correct the magnitudes of all earthquakes. 
Table 1. List of the earthquakes studied. Asterisks in the last column indicate earthquakes not listed in other catalogues (Purcaru, 1979; Utsu, 1990).

\begin{tabular}{|c|c|c|c|c|c|}
\hline \multicolumn{3}{|c|}{ Date } & \multirow{2}{*}{$\begin{array}{l}\text { Depth } \\
(\mathrm{Km})\end{array}$} & \multirow[t]{2}{*}{ Mw } & \multirow{2}{*}{ Remarks } \\
\hline MMM & DD & YYYY & & & \\
\hline Nov. & 24 & 1516 & 150 & 7.5 & \\
\hline- & - & 1543 & 150 & 7.1 & $*$ \\
\hline July & 19 & 1545 & 110 & 7.1 & \\
\hline May & 10 & 1571 & 150 & 7.1 & \\
\hline Apr. & 30 & 1590 & 100 & 7.3 & \\
\hline Apr. & 21 & 1595 & 150 & 7.1 & $*$ \\
\hline Dec. & 24 & 1605 & 150 & 7.1 & \\
\hline Nov. & 08 & 1620 & 150 & 7.5 & \\
\hline Feb. & 01 & 1637 & 130 & 7.1 & \\
\hline Aug. & 09 & 1679 & 110 & 7.5 & $*$ \\
\hline Aug. & 19 & 1681 & 150 & 7.1 & \\
\hline June & 12 & 1701 & 150 & 7.1 & \\
\hline June & 11 & 1738 & 130 & 7.7 & \\
\hline Apr. & 05 & 1740 & 150 & 7.3 & $*$ \\
\hline Apr. & 06 & 1790 & 150 & 7.1 & \\
\hline Oct. & 26 & 1802 & 150 & 7.9 & \\
\hline Nov. & 26 & 1829 & 150 & 7.3 & \\
\hline Jan. & 23 & 1838 & 150 & 7.5 & \\
\hline Aug. & 17 & 1893 & 100 & 7.1 & $*$ \\
\hline Aug. & 31 & 1894 & 130 & 7.1 & \\
\hline Oct. & 06 & 1908 & 125 & 7.1 & \\
\hline Nov. & 10 & 1940 & 150 & 7.7 & \\
\hline Mar. & 04 & 1977 & 94 & 7.4 & \\
\hline Aug. & 30 & 1986 & 131 & 7.1 & \\
\hline
\end{tabular}

Figure 1 depicts the hypocenter distribution of earthquakes in the ROMPLUS catalog. Seismicity in Vrancea is active at depths from 60 to $180 \mathrm{~km}$ (Fig. 1). In the past 1000 years, no earthquake of a magnitude 6.0 or larger has been observed to be shallower than $60 \mathrm{~km}$. Therefore, we targeted earthquakes deeper than $60 \mathrm{~km}$ for our assessment.

Figure 2 illustrates the magnitude-frequency relation for earthquakes with a magnitude of 5.0 and greater for the time period 1500 to 2000 . This figure suggests that earthquakes with a magnitude of 7.0 and greater could be homogeneously detected during this period. We used earthquakes with a magnitude of 7.0 and greater for the time period 1500 to 2000 (Table 1). Table 2 summarizes the results of the likelihood analysis based on the SR-model. We studied three cases, the time periods 1500-2000, 1600-2000, and 1700-2000, respectively. Table 2 also lists the values of $\triangle A I C$ divided by twice the number of main shocks for each case. This value is related to the average probability gain (Imoto, 2001), and the obtained result suggests that the average probability gains of the three cases are more or less similar to one another. The earthquake times and magnitudes are at the top of the figure. The three hazard functions for the different periods exhibit a similar behavior over time (Fig. 3). This confirms that the average probability gains are similar for the three periods.

We can calculate the probability of the next $M \geq 7.0$ earthquake over the next 5 years starting at the year $(t)$ of assessment as follows, under the condition that no earthquake

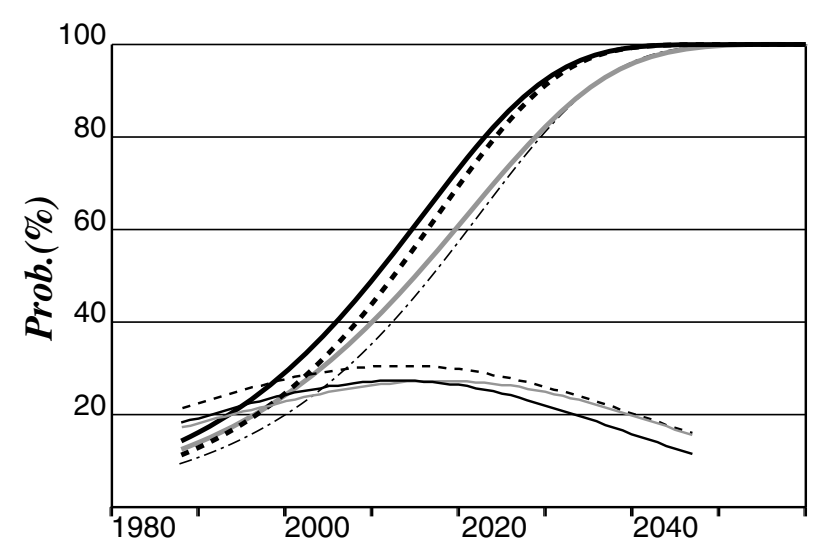

Fig. 4. Probability of the next $M \geq 7.0$ earthquake over the next 5 years (top). Curves at the bottom represent the variances of probability calculated from 1000 sets of simulated data. The results obtained from three different cases are depicted as broken lines (1500-2000), gray lines (1600-2000), and solid lines (1700-2000). The dash-dotted line indicates results obtained from a calculation excluding the five earthquakes with asterisks for the time period 1700-2000.

Table 2. Table of $\triangle A I C$ values for three different periods. The $A I C$ reductions from the Poisson model are given for each case in the second to last column. The optimal values of the model parameters in each case are listed.

\begin{tabular}{c|cccccc} 
Period & $\mathrm{A} 1$ & $\mathrm{~A} 2$ & $\mathrm{~A} 3$ & $\mathrm{~N}$ & $\Delta A I C$ & $\Delta A I C / 2 \mathrm{~N}$ \\
\hline $1500-2000$ & 0.033 & 0.072 & 0.82 & 24 & 12.73 & 0.27 \\
$1600-2000$ & 0.036 & 0.061 & 0.70 & 18 & 7.21 & 0.20 \\
$1700-2000$ & 0.036 & 0.067 & 0.75 & 13 & 5.01 & 0.19
\end{tabular}

has been observed since the 1986 earthquake $(M \geq 7.1 ; t l)$.

$$
\begin{aligned}
P(E \mid t, & t+5) \\
& =\frac{\exp \left\{-\int_{t l}^{t} \lambda(t) d t\right\}-\exp \left\{-\int_{t l}^{t+5} \lambda(t) d t\right\}}{\exp \left\{-\int_{t l}^{t} \lambda(t) d t\right\}} \\
& =1-\exp \left\{-\int_{t}^{t+5} \lambda(t) d t\right\} \quad(t>t l)
\end{aligned}
$$

Figure 4 depicts the probabilities for the three cases, which start with values around $12 \%$ in 1988 and increase with time to more than $30 \%$ in 2005 . The figure demonstrates that the earthquake hazard increases to twice that of the Poisson model at the end of this decade, since the Poisson model estimates about a $20 \%$ probability for a 5 -year period.

To ensure a reliable discussion on calculated probabilities, we evaluated the effects caused by errors in the estimation of magnitude. If error ranges of a magnitude of 0.2 are assumed, errors are randomly generated from a normal distribution and added to the observed values to make 1000 sets of simulated data with perturbations in the magnitude parameter. The variance of probability at each time point can then be calculated using the probabilities of the simulated series. The curves at the bottom of Fig. 4 illustrate the variances obtained in this manner with time for the three different periods; these variances are mostly distributed over a range from 15 to $30 \%$.

A catalogue of historical earthquakes is typically not as reliable as that recorded by instruments. Consequently, we 
obtain slightly different hazard functions (dashed lines in Fig. 3) from those obtained in the ROMPLUS catalogue if we calculate the hazard functions by excluding the five earthquakes with asterisks in the last column in Table 1, which are not listed in other historical catalogues (Purcaru, 1979; Utsu, 1990). The probability of an $M \geq 7.0$ earthquake over the next 5 years calculated from the results for the years 1700-2000 (represented by a dash-dotted line) is about $20 \%$ less than that in ROMPLUS, which is generally within the range of the variance indicated at the bottom of the figure.

\section{Discussion and Conclusions}

Because renewal-process models are used for hazard assessment in both the United States (Working Group on California Earthquake Probabilities, 1999) and Japan (Shimazaki et al., 1999), we compared actual data from renewal models with the results from the SR-model. The four $\triangle A I C$ values, $-9.1,-5.7,-1.2$, and -1.6 , were obtained from four renewal models: the Brownian (Matthews et al., 2002), lognormal, Weibull, and Gamma (Utsu, 1984). Our analysis was based on inter-event times between successive events $(M \geq 7.0)$ for the time period 1600-2000. In all cases where $M \geq 7.0$, the $\triangle A I C$ values were negative, indicating that the renewal models do not fit the data any better than the Poisson model. Similar results were also obtained for years 1500-2000 and 1700-2000. Figure 3 shows that two or more events have frequently been observed within a short time period. This evidence conflicts with an assumption of the renewal models, namely a quasiperiodic feature of events, but the SR-model allows such cases since stress drops caused by earlier events of small size are sometimes not large enough to reduce the existing stress to a level that will produce no additional large events. Accordingly, the SR-model fits the data better than the renewal models. This suggests that the SR-model performs more effectively than the renewal models for long-term assessment of the risk of earthquakes in Vrancea, Romania.

Mârza et al. (1991) estimated annual activity rates for several magnitude classes. Using their rates, the probability for an earthquake $(M \geq 7.0)$ in the next 5 years can be estimated at about $17 \%$. Comparing these values with our results, our estimate for an earthquake $(M \geq 7.0)$ exceeds that calculated from their rates, as of January 2005.

In conclusion, based on the SR-model we estimate that the probability of an earthquake $(M \geq 7.0)$ in the next 5year period to be more than $40 \%$ by the end of this decade.

Acknowledgments. We thank Dr. Mihaela Popa, National Institute for Earth Physics for providing the ROMPLUS catalog. Com- ments by C. F. Shieh and an anonymous reviewer have greatly helped to improve this article.

\section{References}

Akaike, H., On entropy maximization principle, in Applications of Statisticas, edited by P. R. Krishnaiah, 27-41, North Holland, Amsterdam, 1977.

Bebbington, M. and D. Harte, On the statistics of the linked stress release model, Journal of Applied Probability, 38A, 176-187, 2001.

Fuchs, K., K.-P. Bonjer, G. Bock, I. Cornea, C. Radu, D. Enescu, D. Jianu, A. Nourescu, G. Merkler, T. Moldoveanu, and G. Tudorache, The Romanian eartkquake of March 4, 1977, II. Aftershocks and migration of seismic activity, Tectonophysics, 53, 225-247, 1979.

Imoto, M., Application of the Stress Release Model to the Nankai Earthquake Sequence, Southwest Japan, Tectonophysics, 338, 287-295, 2001

Lu, C., D. Harte, and M. Bebbington, A linked stress release model for historical Japanese earthquakes: coupling among major seismic regions, Earth Planets Space, 51, 907-916, 1999.

Mârza, V. I., A. Kijko, and P. Mäntyniemi, Estimate of earthquake hazard in the Vrancea (Romania) region, Pageophysics, 136, 143-154, 1991.

Matthews, M. V., W. L. Ellsworth, and P. A. Reasenberg, A Brownian Model for Recurrent Earthquakes, Bull. Seismol. Soc. Am., 92, 2233 2250, 2002

Nishenko, S. P. and R. Buland, A generic recurrence interval for earthquake forecasting, Bull. Seismol. Soc. Am., 77, 1382-1399, 1987.

Oncescu, M., V. I. Marza, M. Rizescu, and M. Popa, The Romanian earthquake catalogue between 984-1997, Vrancea Earthquakes: Tectonics, Hazard and Risk Mitigation, edited by F. Wenzel et al., pp. 43-47, 1999.

Purcaru, G., The Vrancea, Romania, earthquake of March 4, 1977-a quite successful prediction, Phys. Earth Planet Interiors, 18, 274-287, 1979.

Sakamoto, Y., M. Ishiguro, and G. Kitagawa, Akaike Information Criterion Statistics, Reidel, Dordrecht, 298 pp., 1983.

Shimazaki, K., K. Kawase, K. Satake, Y. Suzuki, Y. Ogata, M. Imoto, and T. Kumamoto, Renewal recurrence models for large earthquakes in Japan, Abstracts, IUGG 22 General Assembly, B, 182, 1999.

Sperner, B., D. Ioane, and R. J. Lillie, Slab behaviour and its surface expression: new insights from gravity modeling in the SE-Carpathians, Tectonophysics, 382, 51-84, 2004.

Utsu, T., Estimation of parameters for recurrence models of earthquakes, Bull. Earthq. Res. Inst., Univ. Tokyo, 59, 56-66, 1984.

Utsu, T., Sekai no Higaizisin no Hyo, Personal Publication, 243 pp., 1990 (in Japanese).

Wenzel, F., F. P. Lorenz, B. Sperner, and M. C. Oncescu, Seismotectonics of the Romanian Vrancea area, Vrancea Earthquakes: Tectonics, Hazard and Risk Mitigation, edited by F. Wenzel et al., pp. 15-25, 1999.

Working Group on Califonia Earthquake Probabilities, Probabilities of large earthquakes in the San Francisco bay region, California: U.S. Geol. Circ. 1053, 51 p., 1990.

Working Group on Califonia Earthquake Probabilities, Earthquake Probabilities in the San Francisco bay region: 2000 to 2030 - A summary of Findings, U.S. Geol. Surv. Open-File Report 99-517, 1999.

Zheng, X. and D. Vere-Jones, Application of stress release models to historical earthquakes from North China, Pageoph, 135, 559-576, 1991.

Zheng, X. and D. Vere-Jones, Further applications of the stochastic stress release model to historical earthquake data, Tectonophysics, 229, 101$121,1994$.

M. Imoto (e-mail: imoto@bosai.go.jp) and N. Hurukawa 